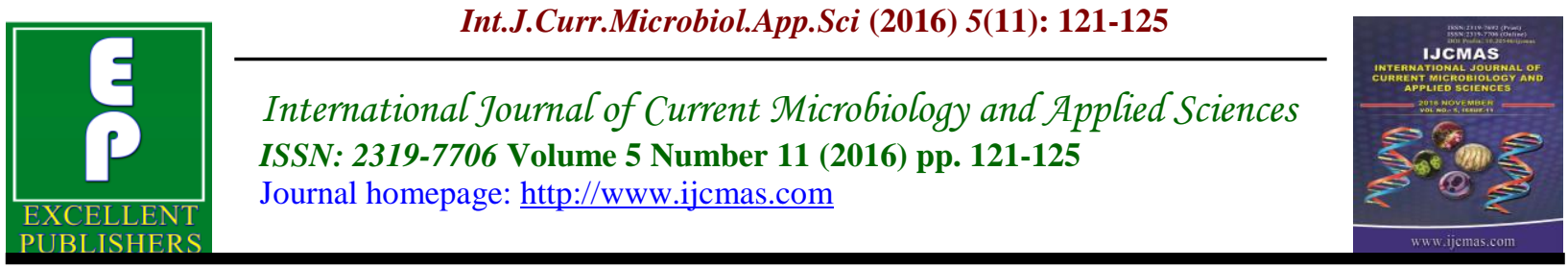

Original Research Article

http://dx.doi.org/10.20546/ijcmas.2016.511.013

\title{
An in vitro Assessment on Fusarium Decomposition in Tea
}

\author{
Pranaba Nanda Bhattacharyya, Prasanta Dutta, Satya Ranjan Sarmah, \\ Amarjyoti Tanti, Mausomi Madhab and Rofika Begum
}

\author{
Mycology and Microbiology Department, Tocklai Tea Research Institute (TTRI), \\ Tea Research Association (TRA), Jorhat 785008, Assam, India \\ *Corresponding author
}

Keywords

Fusarium die-back, micro-climate, Nectria,

tea, tea pathogens.

\section{Article Info}

Accepted:

04 October 2016

Available Online:

10 November 2016

\section{A B S T R A C T}

Tea [Camellia sinensis (L.) O. Kunze] is an aromatic beverage yielding perennial plant. The manufactured tea is commonly prepared by pouring hot or boiling water over cured leaves of the Camellia sinensis, an evergreen shrub native to Asia. After water, it records the most widely consumed drink all over the world. India is the second largest producer of tea in the world after China, including the famous Assam tea and Darjeeling tea. However, as the Indian subcontinent is mostly rain fed and the cropping season also needs a moist climate with alternating wet and dry periods, the micro-climate prevailing the region is, thus, prune for the establishment of major tea pathogens like Fusarium solani, responsible for Fusarium die-back disease. Present findings illustrated the impact of an incubation period of 60 days for maximum decomposition (up to $17.4 \%$ over untreated control) of the Fusarium treated tea twigs. Nectria formation after 60 days of incubation and softening of stem tissue indicated the decomposition of the fungus treated twigs due to the prominent growth of $F$. solani. Three replicates were maintained at each case and all the data were statistically designed.

\section{Introduction}

Tea diseases are considered as important biotic constraint that leads to significant crop losses all over the world (Sharma et al., 2016). The stable micro climatic condition in Indo-Burma Mega Biodiverse region is suitable for the establishment of major tea diseases such as blister blight, black rot, Fusarium die-back, red rust, Poria branch canker etc.

Fusarium die-back is an important disease in the tea growing areas of N. E. India (Barthakur, 2011). Fusarium as a pathogenic fungus, responsible for creating serious maladies to seed as well as the succulent clones (Sharma et al., 2010) in and around the tea plantations. The severities of Fusarium infestation in tea is presently creating devastation among some of the tea sections of Assam and Darjeeling, as the pathogenic attack is sometimes reported as clone specific. Blackening and die-back of tea twigs due to Fusarium infection is becoming a common scenario at most of the tea gardens. In Fusarium die-back, blackening of the leaf petiole occurs that 
gradually extends to the nodes and internodes, followed by wilting of the primaries. According to Barthakur and Debnath, (2011), tea dieback disease caused by $F$. solani is one of the most destructive diseases in North East India responsible for huge crop loss, as it infects the young pluckable shoots. Fungicides namely Copper oxychloride@1:400, Carbendazim @1:400, Copper hydroxide @1:400, Mencozeb@1:400, Hexaconazole@1:1000, Propiconazole @1:1000 were found as effective in controlling the Fusarium dieback disease in tea caused by $F$. solani (Sharma et al., 2010). Kumhar et al (2015) found Trichoderma virens as an effective biocontrol agent against this pathogen and utilized it for the management of die-back. Some planting materials (clones) such as the series of clones of Tocklai Vegetatives such as TV1, TV 19, TV 20, TV 23, TV 25, TV 26, TV 29 and S3A3, S3A1, Tinali17 etc., are more susceptible to the disease. Fusarium may cause extensive damage to tea bushes, even in serious cases leads to bush death. Tea seeds mainly TS 491 and TS 520 and their parent clones are recorded susceptible, resulting in blackening of fruit carp, followed by immature cracking. In affected seeds, the symptom turns into light pinkish due to fungus infestation followed by seed drop. Thus, seed cracking, decaying of some biclonal seed stocks, pre-mature falling of leaves, dyeing of the aerial parts of the productive tea bush due to Fusarium infestation causes considerable losses to the tea industry.

Keeping the point under consideration, an in vitro approach has been designed to understand the effect and severity of Fusarium solani on tea bushes. The time period required by the pathogenic fungus to decompose the planting material is also discussed here. Plant protection code (PPC) for disease management in tea introduced by
Tea Board, Govt. of India, is also mentioned here as part of the control strategies for this emerging disease.

\section{Materials and Methods}

\section{Sample collection}

Twigs of mature tea, Tocklai Vegetative clone (TV1) were collected from experimental garden of Tocklai Tea Research Institute (TTRI), Tea Research Association (TRA), Jorhat 785008, Assam, India. Fusarium solani strain was taken from the Culture Stock Laboratory (CSL) of the Mycology and Microbiology Department, TTRI, TRA, Jorhat. The pure culture was sub-cultured and used separately for the present experimental purpose.

\section{In vitro assessment of Fusarium decomposition}

The method described by Wei et al., (2013) was followed to determine the fungal decomposition. For this, the collected tea twigs were properly washed and chopped into pieces of approximately $1.0 \mathrm{~cm}$ in size and soaked in $4 \%$ sugar solution for $3 \mathrm{hrs}$. The sugar solution was drained out, keeping only the treated twigs. Nine consecutive conical flasks $(500 \mathrm{ml})$ each containing 100 gm of treated twig pieces were sterilized in an autoclave at $121{ }^{0} \mathrm{C}$ (equivalent to 15 $\mathrm{lb} / \mathrm{inch}^{2}$ ) for 15-20 mins. After sterilization, the treated pieces were inoculated with fresh strain of $F$. solani, the responsible pathogen for causing Fusarium die-back disease in tea. The flasks were further incubated at 26 ${ }^{0} \mathrm{C}$ in an incubator and observations for changing weight of the flasks as well spore development were recorded after 30, 45 and 60 days of incubation. Another set of flask was taken as control, which consists of cut tea twigs without Fusarium inoculation. Finally, the decomposition rate of the tea 
twigs with $F$. solani was calculated and compared with control. The data were statistically analyzed.

\section{Results and Discussion}

Maximum decomposition of the Fusarium treated tea twigs were observed after 60 days of incubation (Table 1). The decomposition was up to17.4\% over untreated control. The initial weight of the treated tea twigs also showed a progressive reduction with increase in incubation period over untreated control. On the other hand, the untreated twigs (control) showed minimum weight loss due to evaporation and, thus, they remained as dry and healthy. Plant material decomposition is often considered as microbial composting activities (Awasthi et al., 2012). Fig. 1 shows the photographs of Fusarium treated tea twigs after 45 days of incubation compared with untreated control. Fusarium infestation was comparatively less on the tea twigs that were initially kept for 30 days of incubation period.

However, there are appearances of small orange colored fructifications after incubation of the tea samples for 45 days. Softening of the stem tissue followed by mature Nectria development (orange colored fruiting bodies) after 60 days of the incubation experiment indicated the decomposition of the fungus treated twigs due to the prominent growth of $F$. solani (Fig. 2a-c). Variations in the Fusarium decomposition in tea might be attributed to the change in incubation periods and developed moisture content in the stored samples. It is inferred that the temperature and incubation time period considered in microbial decomposition process is a good indicator of the bio-oxidative phase till its time of completion (Buyuksnomez et al., 2000). Decomposition process gets matured when the temperature remains more or less constant and does not vary with the turning of the material.

Table.1 Fusarium decomposition in tea in different time intervals.

\begin{tabular}{|c|c|c|c|c|}
\hline $\begin{array}{l}\text { Target } \\
\text { Specimen }\end{array}$ & $\begin{array}{c}\text { Initial } \\
\text { weight (g) }\end{array}$ & & $\begin{array}{c}\text { Final } \\
\text { weight }(g\end{array}$ & \\
\hline \multirow{8}{*}{$\begin{array}{l}\text { Fusarium } \\
\text { inoculated tea twigs } \\
\text { Control } \\
\text { Rate } \\
\text { decomposition over } \\
\text { control (\%) }\end{array}$} & & \multicolumn{3}{|c|}{ Incubation time } \\
\hline & & 30 Days & 45 Days & 60 Days \\
\hline & 100 & 97.2 & 86.3 & 80.5 \\
\hline & 100 & 99.85 & 99.24 & 98.13 \\
\hline & & 2.65 & 13.0 & 17.4 \\
\hline & $\mathrm{CD}$ at $5 \%$ & 0.0863 & 0.6233 & 0.0853 \\
\hline & CV (\%) & 0.0521 & 0.3996 & 0.057 \\
\hline & $\operatorname{SEM}( \pm)$ & 0.030 & 0.21 & 0.030 \\
\hline
\end{tabular}

$*$ Data are the mean of three replicates, $\pm \mathrm{S}$. D. 
Fig.1(a-f) Photographs showing control (a-c) and Fusarium treated tea twigs (d-f) after 45 days of incubation.

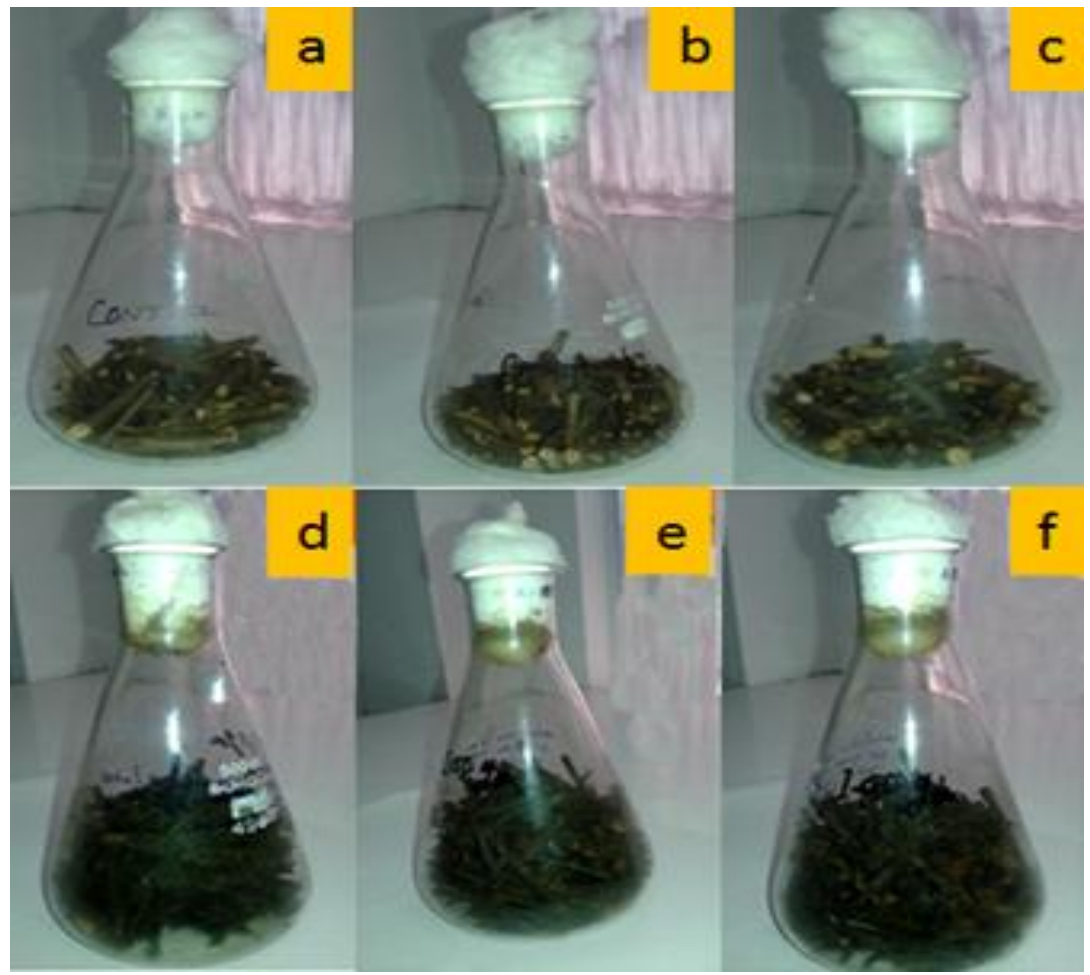

Fig.2(a-c) Photographs showing stages of Nectria development after 60 days of incubation.

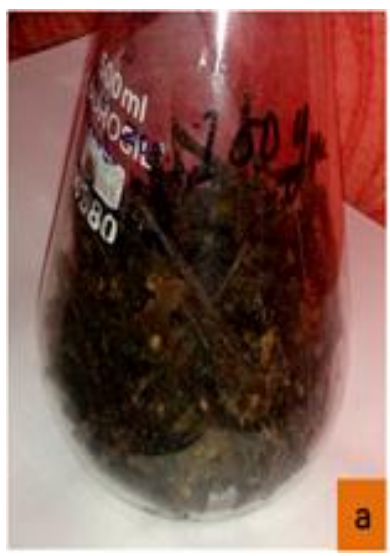

\section{Management practices}

The concept of tea disease management has undergone a considerable change over the last few decades. Presently, spraying with Hexaconazole@1:1000, two rounds at 15 days interval have been suggested for

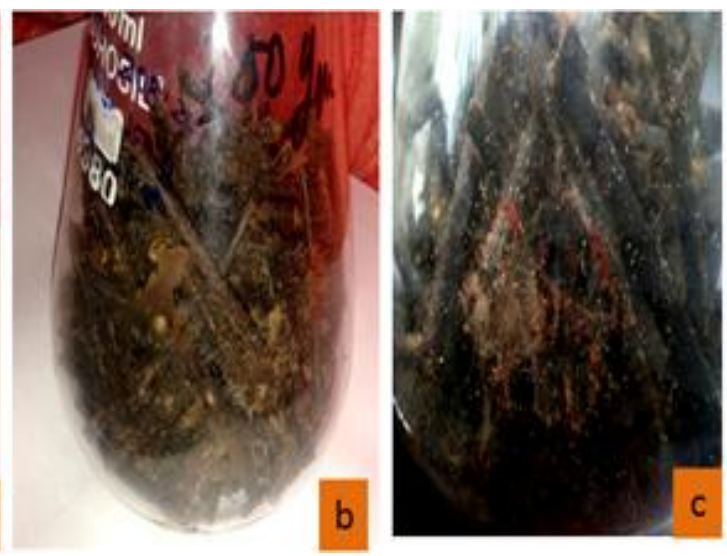

application on Fusarium infected tea bushes for effective management. While, in case of seed infection, application with Hexaconazole @ 1:1000, in the affected seed baries in every month starting from July to December is recommended. As part of integrated disease management programme, 
efforts have also been generated and popularized by TTRI, TRA to adopt nonchemical control approaches. The infected shoots should be cut and burned properly away from the diseased sections. Infected sections should preferebly undergo shorter prunning cycles. There is also potentiality in using herbal extracts as well as antagonistic microbials as an alternative safer technology in reducing the die-back disease severity in tea plantations of Assam, N. E. India (Sharma et al., 2009).

\section{Acknowledgements}

The authors are thankful to the Director, Tocklai Tea Research Institute (TTRI), Tea Research Association (TRA), Jorhat, Assam, India for providing the necessary facilities to undertake the study.

\section{References}

Awasthi, M.K., Bundela, P.S., Pandey, A.K., and Jamaluddin. 2012. Monitoring of microbial population and their activities during composting of organic municipal solid wastes at central India. Int. J. Plant Animal Environ. Sci., 2: 26-36.

Barthakur, B.K. 2011. Recent approach of Tocklai to plant protection in tea in North-east India. Sci. Cult., 77: 381-384.

Barthakur, B.K., and Debnath, S. 2011. Disease management of tea in Darjeeling. In: Field management in tea- Darjeeling. Tea Research Association, NBRRDC, Nagrakata 735225, West Bengal. pp. 137142.
Buyuksnomez, F., Ryank, R., Hess, T., and Bechinski, E. 2000. Occurrence, degradation and fate of pesticides during composting. Part II: occurrence and fate pesticides in compost and composting systems. Compost Sci. Util., 8: 61-81.

Kumhar, K.C., Babu, A., Bordoloi, M., Banerjee, P., and Dey, T. 2015. Biological and chemical control of Fusarium solani, causing dieback disease of tea Camellia sinensis (L): an in vitro study. Int. J. Curr. Microbiol. Appl. Sci., 4: 955-963.

Sarmah, S.R., Baruah, P.K., Das, S.C., and Barthakur, B.K. 2009. Evaluation of few herbal extracts and microbial bio-agents on vegetative growth of Fusarium sp. isolated from tea [Camellia sinensis (L.) O. Kuntze]: an in-vitro approach. Proceedings of national seminar on exploitation, utilization and strategy action plan for sustainable management of plant resources, Department of Botany, Gauhati University, p. 77.

Sarmah, S.R., Baruah, P.K., and Das S.C. 2010 Effect of different fungicides on die back disease of tea plant. J. Adv. Plant Sci., 5: 92-96.

Sarmah, S.R., Dutta, P., Bhattacharyya, P.N., Payeng, B., and Tanti, A. 2016. Growth habit of tea pathogens (Cephaleuros spp. and Fusarium solani) and evaluation of relative susceptibility of selected tea cultivars. Int. Res. J. Biol. Sci., 5: 1-9.

Wei, D., Schmidt, O., and Liese, W. 2013 Method to test fungal degradation of bamboo and wood using vermiculite as reservoir for moisture and nutrients. Maderas. Ciencia y tecnologia, 15, 349356.

\section{How to cite this article:}

Pranaba Nanda Bhattacharyya, Prasanta Dutta, Satya Ranjan Sarmah, Amarjyoti Tanti, Mausomi Madhab and Rofika Begum. 2016. An in vitro Assessment on Fusarium Decomposition in Tea. Int.J.Curr.Microbiol.App.Sci. 5(11): 121-125.

doi: http://dx.doi.org/10.20546/ijcmas.2016.511.013 